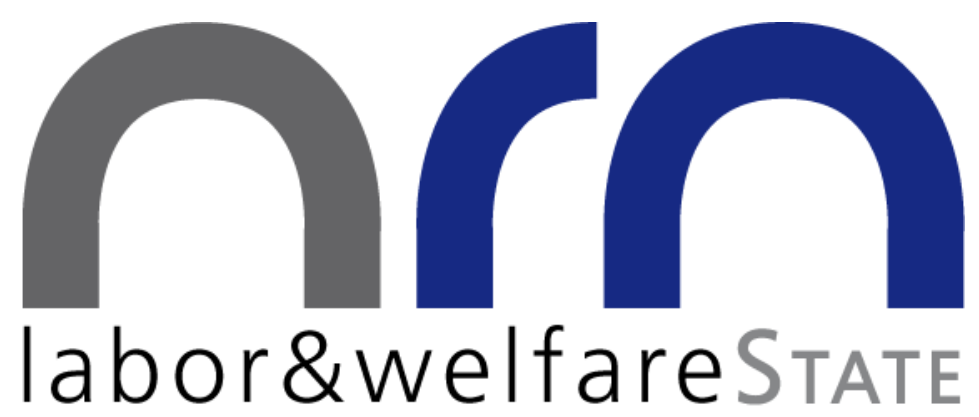

The Public Perception and Normative Valuation of Executive Compensation: An International Comparison

by

Andreas $\mathrm{KUHN}^{*}$

Working Paper No. 1013

November 2010

Supported by the Austrian Science Funds

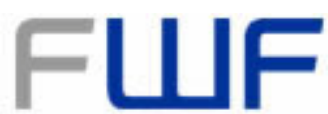

The Austrian Center for Labor Economics and the Analysis of the Welfare State

University of Zurich

Department of Economics

Mühlebachstrasse 86

8008 Zurich, Suisse

www.labornrn.at 


\title{
The Public Perception and Normative Valuation of Executive Compensation: An International Comparison
}

\author{
Andreas Kuhn, University of Zurich and IZA*
}

November 2010

\begin{abstract}
This paper describes individuals' perceptions and normative valuations of executive compensation using comparable survey data for fifteen OECD member countries. An overwhelming majority of individuals (more than $90 \%$ ) believes that top executives earn more than they actually deserve. However, there is also substantial variation in the actual and ethical levels of executive compensation, both within and across countries. The empirical analysis further shows that subjective estimates of executive pay are associated with objective measures of inequality and redistribution, and that individuals' perceptions and normative valuations of executive compensation are associated with their more general political preferences.
\end{abstract}

JEL classification: D31, D63, J31

Keywords: executive compensation, subjective wage estimates, political preferences

\footnotetext{
${ }^{*}$ I thank Andreas Steinhauer for superb research assistance. Financial support by the Austrian Science Fund ("The Austrian Center for Labor Economics and the Analysis of the Welfare State") is gratefully acknowledged. Contact: Andreas Kuhn, University of Zurich, Department of Economics, Mühlebachstrasse 86, 8008 Zurich, Switzerland; andreas.kuhn@econ.uzh.ch.
} 


\section{Introduction}

"If you really believe 91 million Swiss francs is a fair salary, then perhaps you still believe in the Easter bunny and Santa Claus as well." 1

Top executive compensation has increased substantially in recent years. For example, Bebchuk and Grinstein (2005) document that the average compensation for chief executives of S\&P 500 firms increased from $\$ 3.7$ million in 1993 to $\$ 9.1$ million in 2003 , which corresponds to a relative increase in compensation of about $245 \%$. Because the distribution of CEO pay is highly skewed, simple averages may be somewhat misleading with regard to the average executive's compensation. Nonetheless, Clementi and Cooley (2009) find a similar pattern for the median compensation for CEOs of S\&P firms. Moreover, Frydman and Saks (2010) use longer-run data on executive pay for the US and show that this sharp increase is indeed a recent phenomenon and that median executive compensation was rather flat until the 1970s. Similar trends in top executive compensation are observable in other countries. ${ }^{2}$

While these studies provide evidence on the effective level and trend of executive compensation $^{3}$, virtually nothing is known about individuals' subjective perceptions and normative evaluations of top executive compensation. To the best of my knowledge, there is only one single empirical study by Jasso and Meyersson Milgrom (2008) on the fairness of executive pay from individuals' subjective points of view. In this study, Jasso and Meyersson Milgrom asked MBA students from Sweden and the United States about the ethical compensation of top executives. Even within their rather homogeneous sample of business students, they find that individuals hold widely different beliefs about fair compensation for executives. However, as the study relies on a sample of business students, a very narrow group of individuals who

\footnotetext{
${ }^{1}$ Cédric Wermuth, president of the Young Socialist party of Switzerland, addressing Credit Suisse's chief executive Brady Dougan at the annual meeting of the bank on April 30, 2010. The quote is taken from the online edition of The Wall Street Journal (http://blogs.wsj.com/source/2010/04/30/yes-brady-dougan-there-isa-santa-claus).

${ }^{2}$ See Abowd and Kaplan (1999) for cross-country evidence, Conyon et al. (1995) for the UK, Zhou (2000) for Canada, and Conyon and Murphy (2000) for a comparison between the US and the UK. Evidence for other countries is hard to come by, mainly because most other countries do not require detailed disclosure of the compensation of top executives. Kaplan and Rauh (2010) document similar trends in compensation for non-managerial high-wage earners.

${ }^{3}$ There is not much disagreement about changes in the level of top executive compensation, but economists have put forward different theoretical models of executive compensation (see Murphy, 1999, for a comprehensive survey). Explanations based on competitive mechanisms rank prominently within the field of economics (e.g. Gabaix and Landier, 2008; Jensen and Murphy, 1990), but some researchers also argue that executive pay is in fact only loosely related to top executives' actual performance (e.g. Bebchuk and Fried, 2003; Bertrand and Mullainathan, 2001).
} 
likely have specific beliefs about the ethical level of executive compensation, their data are unlikely to reveal more general normative evaluations of executive compensation. ${ }^{4}$ Moreover, while Jasso and Meyersson Milgrom can study how CEO characteristics influence students' judgments of the fair level of executive compensation, their data does not allow them to relate individuals' subjective estimates of compensation to objective indicators of inequality.

This paper documents the perceived and the ethical level of top executive compensation of the general population from the subjective point of view. Specifically, the empirical analysis uses internationally comparable survey data for sixteen OECD member countries to study the empirical distribution of individuals' subjective perceptions and normative valuations of top executive compensation and how these perceptions and beliefs relate to individual characteristics and aggregate measures of objective inequality. The empirical analysis is based on individuals' subjective estimates of both actual and ethical compensation of top executives. Not surprisingly, I find considerable variation in these estimates across both individuals and countries. The data also show that a clear majority of all individuals (more than 90\%) believes that top executives earn more than they deserve, i.e. the ethical level of executive compensation tends to be lower than the perceived level of compensation. This general pattern notwithstanding, however, there are large national differences in subjective estimates of both actual and ethical executive compensation.

The empirical analysis further shows that, while individual-level regressors explain a substantial part of the observed variation in subjective estimates of executive pay, substantial and significant differences remain between the countries considered in the empirical analysis. Interestingly, country-level characteristics such as the effective level of inequality (measured simply by the Gini coefficient in disposable household income) can explain part of these remaining differences. One potential explanation for this empirical pattern is that subjective perceptions of and normative beliefs about executive compensation are associated with individuals' political preferences, such as their support for progressive taxation, which may in turn reflect on the effective level of executive compensation. ${ }^{5}$ For example, it is easily imaginable

\footnotetext{
${ }^{4}$ Indeed, there is evidence that economics students behave differently in experiments than students from other fields (e.g. Frank et al., 1993). It has also been shown that taking courses in economics may strengthen students' beliefs in the fairness of market outcomes (Whaples, 1995).

${ }^{5}$ There is some indirect evidence that individuals' subjective perceptions of executive compensation feed back into economic outcomes. For example, Charness and Levine (2000) show that people view layoffs to be more acceptable if downsizing is not accompanied with bonuses for top executives. There is even evidence that
} 
that people who are disturbed by executive compensation are also inclined to vote for those politicians who promise tighter regulation of executive compensation. Indeed, the empirical analysis shows that people who perceive executive compensation to be too high tend to be more in support of state redistribution and progressive taxation. In view of this evidence, it seems likely that these individuals are also more likely to favor of policies that restrict top executive compensation more directly.

The remainder of this paper proceeds as follows. The next section describes the data source and the construction of the key variables (i.e. subjective estimates of executive pay). This section also presents extensive descriptive evidence in this section, especially emphasizing differences perceptions and valuations between countries. Section 3 discusses the econometric framework used for the analysis of the determinants of subjective estimates of executive pay and for that of the relation between individuals' subjective estimates of executive pay and their more general political preferences. Section 4 concludes.

\section{Subjective Estimates of Executive Compensation}

\subsection{Data Source}

I rely mainly on data from the International Social Survey Program (ISSP), a collaboration of several national survey organizations. The ISSP administers one survey each year on different main themes, among them issues surrounding social inequality. I use data from the 1999 survey on social inequality ("Social inequality III") for the present analysis, and focus on OECD member countries only. ${ }^{6}$

\subsection{Key Measures}

Among other things, individuals were asked to estimate what they perceived to be the actual wage of people working in different occupations ("actual wage"), and what they thought that a person working in one of these occupations should actually earn in their subjective view ("ethical wage"). One of the occupations for which individuals were asked to give actual and

the perceived unfairness of executive compensation feeds back into individuals' actual work effort (Cornelissen et al., 2010).

${ }^{6}$ The following countries/regions are included in the empirical analysis: Australia, Austria, Canada, the Czech Republic, (former Eastern and Western) Germany, France, Great Britain, Norway, New Zealand, Poland, Portugal, Slovakia, Sweden, and the United States. 
ethical wage estimates is "the chairman of a large national company". Specifically, individuals were asked two specific questions about earnings for people working in different occupations (the wording is taken from the original source questionnaire of the ISSP):

- "We would like to know what you think people in these jobs actually earn. Please write how much you think they actually earn each month (before taxes and social security contributions). Many people are not exactly sure about this, but your best guess will be close enough."

- "Next, what do you think people in these jobs ought to be paid. How much do you think they should earn each month (before taxes and social security contributions), regardless of what they actually earn."

In the following, $y(i)_{j}^{\text {actual }}$ and $y(i)_{j}^{\text {ethical }}$ will denote, respectively, an individual's estimate of the actual and ethical compensation for an individual working in occupation $j$. Based on these simple estimates, I construct the following two variables to capture individuals' perception of the actual and their belief regarding the ethical level of executive compensation (actual and ethical compensation, respectively, for short): ${ }^{7}$

$$
\begin{gathered}
y(i)^{\text {actual }}=y(i)_{\text {chairman }}^{\text {actual }} / y(i)_{\text {worker }}^{\text {actual }} \\
y(i)^{\text {ethical }}=y(i)_{\text {chairman }}^{\text {ethical }} / y(i)_{\text {worker }}^{\text {ethical }}
\end{gathered}
$$

I normalize individuals' estimates of executive pay using their corresponding estimate of the actual or ethical compensation of a skilled factory worker (worker, for short) to eliminate country differences regarding the scaling of these estimates (see also footnote 7 ). ${ }^{8}$ This normalization, however, introduces some ambiguity, as variation in these two measures not only reflects variation in estimates of executive compensation but also different evaluations of a skilled worker's wage. To take this issue into account, I will also include several additional regressors based on individuals' assessment of wages in other occupations later on in the

\footnotetext{
${ }^{7}$ Obviously, individuals' estimates of actual compensation do not necessarily reflect the real level of executive compensation. Indeed, Osberg and Smeeding (2006, Table 5) find that there are large discrepancies between the effective level of executive pay and individuals' estimates of actual compensation for top executives. At the same time, however, they only find small discrepancies for the compensation of a skilled worker in manufacturing.

${ }^{8}$ Besides the need to convert estimates into one common currency, estimates from different countries also relate to different units of time (i.e. monthly or annual earnings).
} 
empirical analysis (see section 3 below as well as appendix A). ${ }^{9}$

An individual's desired change in executive compensation is measured as the relative difference between ethical and actual estimate of executive pay:

$$
\begin{aligned}
\Delta y(i) & =\ln \left(y(i)_{\text {chairman }}^{\text {ethical }} / y(i)_{\text {chairman }}^{\text {actual }}\right) \\
\widehat{\Delta} y(i) & =\ln \left(y(i)^{\text {ethical }} / y(i)^{\text {actual }}\right) \\
& =\left[\ln \left(y(i)_{\text {chairman }}^{\text {ethical }}-\ln \left(y(i)_{\text {chairman }}^{\text {actual }}\right)\right]-\left[\ln \left(y(i)_{\text {worker }}^{\text {ethical }}-\ln \left(y(i)_{\text {worker }}^{\text {actual }}\right)\right]\right.\right.
\end{aligned}
$$

The first measure, given by equation (3a), is approximately equal to the relative difference between an individual's ethical and actual estimate of executive compensation. Note that the second term on the right-hand-side of (3b) also takes the desired change in a skilled worker's compensation into account. Because this term turns out to be positive for most people, $(3 \mathrm{~b})$ tends to be larger than (3a). Nonetheless, the sample correlation between these two measures is as high as 0.88 . See also panel (a) of table 1 (which is discussed in more detail below). ${ }^{10}$

\subsection{Descriptive Statistics}

I start with a simple description of some key features of these subjective measures of executive compensation of the data pooled across all countries (country differences are discussed below). Panel (a) of figure 1 plots the frequency distribution of individuals' estimates of actual executive compensation. ${ }^{11}$ The distribution of this measure is highly skewed, with values ranging from one to more than seventy. Panel (b), in contrast, shows individuals' estimates of a chairman's ethical wage. This measure is also highly skewed to the right, but it has a much smaller range than actual executive compensation (observed values range from around two-thirds of to about thirty times a worker's wage). The discrepancy in the distribution of the two measures is more easily evident in panel (c), which plots the two corresponding cumulative density functions. The figure highlights the substantial shift in distribution when going from actual to ethical

\footnotetext{
${ }^{9}$ Using an individual's estimate of an unskilled worker's wage to normalize estimates of executive compensation yields very similar results. The sample correlation between the two alternative estimates of actual (ethical) executive pay is as high as $0.8652(0.8850)$.

${ }^{10}$ As detailed in appendix A, I construct several additional variables from these wage estimates that are used as explanatory variables below when modeling the variation of subjective measures of executive compensation.

${ }^{11}$ Note again that this variable serves to measure an individual's perception of executive compensation and that the normalization using the estimate of a skilled worker's wage not only serves to eliminate different scaling due to different currencies, but also to net out differences in individuals' perceptions of the overall level of wages.
} 
executive compensation (see also table 1 below), pointing to the fact that most people think that top executives earn more than they actually deserve.

Figure 1

Figure 2 shows the distribution of individuals' desired change in executive compensation, using two alternative measures. More specifically, panel (a) plots the distribution of the natural logarithm of the ratio of an individual's ethical over his or her actual estimate of a chairman's compensation. Even though there is a clear spike at zero (denoting that actual and ethical compensation coincide), it is apparent from panel (a) that most people would like a decrease in executive pay (relative to the perceived level of actual compensation) and that the desired change is often substantial in size (see also table 1 below). Panel (b) also shows desired changes in executive compensation, taking the desired change for a skilled worker's wage into account, however (see appendix A for details). This still yields a skewed distribution with mostly negative values, but also a less pronounced spike at zero. Panel (c) shows the cumulative density function of these two variables. ${ }^{12}$

Figure 2

Overall, note that all people perceive the actual compensation of a chairman to be at least as high as the wage of a skilled worker and that most people also believe that a chairman should be paid at least as much as a skilled worker. At the same time, most individuals would also support a decrease in executive compensation relative to the level of pay which they perceive to exist in reality. In this sense, a majority of individuals thinks that top executives earn more than they deserve. Also note that a significant fraction of individuals thinks that executive compensation is fair, in the sense that they give exactly identical estimates of actual and ethical executive pay. However, taking desired changes in a skilled worker's wage into account decreases this fraction substantially, from almost $25 \%$ to less than $10 \%$ (compare panels (a) and (b) in figure 2).

Table 1

\footnotetext{
${ }^{12}$ Note that about $69 \%$ and $88 \%$ of all individuals, respectively, would like to see a decrease in executive pay (relative to the perceived level of compensation), depending on which of the two measures we look at. Thus only a small fraction of individuals would favor an increase in executive pay (about $8 \%$ and $5 \%$, respectively).
} 
Table 1 provides additional descriptive information. First, panel (a) shows summary statistics for individuals' estimates of executive compensation. On average, a chairman's actual compensation is estimated to be more than nine times as high as a skilled worker's wage, while the ratio of ethical executive compensation to ethical skilled workers' wages is only about 4.1 on average. Consequently, most individuals think that a chairman earns more than what they would judge as ethical compensation. On average, individuals would favor a decrease in executive pay by about $34.6 \%(=100 \% \cdot[\exp (-0.425)-1])$. Taking the fact that most people would also like to increase a skilled worker's wage into account, this yields an even larger figure of about $49.3 \%(=100 \% \cdot[\exp (-0.68)-1])$. Panel $(b)$ shows descriptives for additional variables which are also constructed from individuals' subjective wage estimates (but for occupations other than a chairman). ${ }^{13}$ The first two of these measures describes individuals' perceptions and normative valuations, respectively, of overall wage differentials across occupations (other than executives). The average ratio of highest to lowest perceived wage is about 18 , while the corresponding ratio of highest to lowest ethical wage is only slightly larger than 8 . The next two variables are meant to capture an individual's desired change regarding a skilled worker's wage and that of his or her coworkers, respectively. In both cases, individuals estimate ethical wages higher than actual wages on average. The ratio of ethical to actual wages for a skilled worker is 1.356 and 1.474 for one's coworkers. Finally, the ratio of one's coworkers' wage to the wage of a skilled worker is used to control for an individual worker's own wage level. ${ }^{14}$ On average, individuals estimate that their coworkers earn about 1.435 times the wage of a skilled worker. Descriptive statistics for additional individual-level controls used later in the regression models are given in panel (c) of table 1 (see appendix table A for details regarding the construction of these variables). Besides the usual socio-demographic controls (age, gender, and education), I also use two variables describing people's perceptions of what determines actual pay (ascribed and/or acquired skills) as well as two additional variables describing individuals' normative beliefs about what should be important in determining pay (needs and/or personal effort). I further include a variable that measures individuals' perception of social conflicts (e.g. conflicts between the poor and the rich) and an index of social mobility. Finally,

\footnotetext{
${ }^{13}$ Definitions of and additional details about these variables are given in appendix A.

${ }^{14}$ As mentioned above, I also include measures involving a skilled worker's wage because both actual and ethical estimates of executive pay are normalized using wage estimates for skilled workers (according to equations (1) and (2)).
} 
panel (d) shows descriptives for those three country-level variables that are also included as explanatory variables in the regression analysis below. The first measure is the Gini coefficient of disposable household income before taxes and transfer payments. The second measure is the difference in the Gini before taxes and transfers and the Gini after these deductions. This variable captures the effective impact of redistributive policies on the market distribution of income. The third and final aggregate measure is real per capita gross domestic product. ${ }^{15}$

\section{Country Differences}

It is of special interest to know whether there are differences in average subjective estimates of executive pay across countries and whether these differences, if present, are associated with differences in objective measures of inequality and redistribution. To explore this issue empirically, panel (a) of figure 3 first shows that both average perceptions and average normative evaluations vary widely across countries. With respect to actual estimates, we can see that Norway ranks lowest among all countries considered, with an average estimate of actual executive compensation of 3.56 times a skilled worker's wage. France ranks highest with an average estimate of about 17 times the wage of a (skilled) worker. Nonetheless, the overall pattern is not surprising, showing that most Eastern European countries and the Anglo-American countries rank higher than the other European countries. Even though not readily evident from the figure, there is still a clear national-level ranking with regard to ethical estimates of executive pay. Interestingly, the figure also shows that average perceptions have much larger between-country variation than average ethical assessments. Panel (b), on the other hand, shows country means for the ratio of ethical to actual executive compensation. Compared to panel (a), the ranking of countries is roughly reversed, with the Anglo-American countries and France at the one end (with a low average ratio of ethical to actual compensation) and the Eastern European countries at the other end (with a high average ratio of ethical to actual pay).

Figure 3

To further explore the issue of country differences in estimates of executive compensation, the last column in panel (a) of table 1 shows the intraclass correlation for the different variables

\footnotetext{
${ }^{15}$ The two Gini coefficients refer to the mid-1990s and are taken from OECD (2008). Real per-capita GDP in 1999 is taken from the Penn World Table.
} 
related to executive pay. ${ }^{16}$ Interestingly, the results show that there is significant withincountry correlation regarding both actual and ethical estimates of executive pay: variation in country-specific averages drive about $15 \%$ and $10 \%$ of the overall variance in actual and ethical estimates of executive compensation, respectively. In contrast, the intraclass correlation is much smaller for the two measures of the desired change in executive pay. This implies that there are more pronounced country differences with respect to the perception and the normative valuation than to the desired change in executive compensation. However, panel (b) shows that the intraclass correlation is also large for other measures that involve individuals' estimates of occupational wages. For example, the intraclass correlation with respect to individuals' estimates of overall wage differentials across occupations amounts to about 0.18 in the case of actual wage estimates and to about 0.11 in the case of ethical wage estimates, respectively.

\section{Figure 4}

Additionally, figure 4 shows some simple scatterplots at the country level. Panel (a) shows a surprisingly close association between average estimates of actual and ethical executive compensation. It also shows that the two Nordic countries, Norway and Sweden, together with Slovakia on one end and France on the other end of the scale stand out from the rest of the countries. Panels (b) and (c) show that the desired reduction in executive pay is closely linked to both the perception of actual and the normative evaluation of ethical executive pay, respectively. The remaining three panels show scatterplots involving both subjective estimates of executive compensation and objective measures of inequality. First, panel (d) shows the association of actual compensation versus objective inequality before and after taxes and transfer payments, respectively. Clearly, individuals' perception of executive compensation is higher in those countries where the actual level of inequality is higher (this holds true regardless of whether objective inequality is measured before or after taxes and transfer payments). A very similar pattern is found with for executives' ethical compensation, as shown in panel (e). The ethical level of executive compensation is thus also higher in those countries with a higher level of effective income inequality. Finally, panel (f) shows that the desired reduction in executive pay tends to be larger in less equal countries.

\footnotetext{
${ }^{16}$ The intraclass correlation is defined as the ratio of group-level variance (i.e. the variation of country means relative to the overall mean) to the overall variance of any given variable. A high intraclass correlation results if individuals within the same countries have similar characteristics and individuals from different countries have different characteristics.
} 
Overall, the descriptive evidence points to a potential association between objective inequality measures on the one hand and individuals' subjective perceptions and normative valuations of executive pay on the other. It remains to be shown, however, that this association is robust to an analysis that controls for differences in individual-level regressors. I next turn to an econometric analysis that includes both individual and country-level predictors of subjective perceptions and ethical valuations of executive pay.

\section{Empirical Analysis}

\subsection{Econometric Framework}

I assume that the statistical model for any considered subjective measure of executive compensation is given by the following equation:

$$
y_{i j}=\beta_{0}+x_{i j} \beta+z_{j} \gamma+\varepsilon_{i j}
$$

where $y_{i j}$ either denotes the actual/ethical estimate of executive pay or the desired change in executive compensation of individual $i$ in country $j$. Vector $x_{i j}$ denotes control variables which vary at the individual level while $z_{j}$ denotes control variables which only vary at the country level (which I will explain below). The regression error term $\varepsilon_{i j}$ is assumed to be independent of both $x_{i j}$ and $z_{j}$.

Because there is considerable within-country correlation both with respect to the perception and the normative valuation of executive pay (as documented in the preceding section), I will allow the error terms of observations from the same country to be potentially correlated. To do so I assume that the error term $\varepsilon_{i j}$ consists of two distinct components that are independent of each other (e.g. Gelman and Hill, 2007):

$$
\varepsilon_{i j}=\zeta_{j}+\epsilon_{i j}
$$

The compound error term $\varepsilon_{i j}$ is thus assumed to consist of a country-specific part $\zeta_{j}$ and an individual-specific part $\epsilon_{i j}$. This in turn implies that the model for outcome $y_{i j}$ can be 
written as follows:

$$
\begin{aligned}
y_{i j} & =\beta_{0}+x_{i j} \beta+z_{j} \gamma+\left(\zeta_{j}+\epsilon_{i j}\right) \\
& =\left(\beta_{0}+z_{j} \gamma+\zeta_{j}\right)+x_{i j} \beta+\epsilon_{i j}
\end{aligned}
$$

The second equality in (6) shows that we now have a statistical model for outcome $y_{i j}$ with a random, country-specific intercept (i.e. a random coefficient). The parameters of the model are identified by assuming that the distributions of the two error components are distributed as follows (e.g. Rabe-Hesketh and Skrondal, 2008):

$$
\begin{aligned}
\zeta_{j} \mid x_{i j}, z_{j} & \sim N\left(0, \psi^{2}\right), \quad \text { and } \\
\epsilon_{i j} \mid x_{i j}, z_{j}, \zeta_{j} & \sim N\left(0, \theta^{2}\right)
\end{aligned}
$$

The variances in the two error components $\psi^{2}$ and $\theta^{2}$, respectively, are also parameters that are estimated along with the usual regression parameters $\beta_{0}$ and $\beta$. The assumptions regarding the distribution of the two error components imply that the compound regression error term $\varepsilon_{i j}$ from equation (4) may be correlated for any pair of individuals from the same country (because of the common country-specific component $\zeta_{j}$ ), but that individual error terms are otherwise independent from one another. There are two features that make an econometric model like this one attractive in the present context. First, the model allows the inclusion of both individual-level and country-level regressors. Second, standard errors are adjusted for the potential within-country correlation of the error terms and thus also account for the fact that the coefficients of the country-level regressors are usually much less precisely estimated than coefficients on individual-level regressors (e.g. Moulton, 1986).

I include several variables at the individual level describing an individual's subjective perceptions of actual and valuations of ethical compensation with respect to different occupations (other than a chairman), an individual's normative beliefs regarding distributive justice, his or her perceptions of determinants of effective pay, as well as several socio-economic control variables such as respondents' age and education (see appendix A for details). At the aggregate level, I include less than a handful of economic variables. Specifically, I include the Gini coefficient with respect to disposable household income (before taxes and transfer payments) 
as objective inequality measure, and the difference between the Gini before taxes and transfers minus the Gini after these deductions as a measure for the impact of redistributive policies on inequality. Finally, I also include the real per capita gross domestic product to control for the absolute income level in a country (data sources are given in footnote 15). ${ }^{17}$

\subsection{Determinants of Individuals' Estimates of Executive Pay}

Table 2 shows the main results using random-effects models. The dependent variable in the first column is the log of actual executive compensation, the log ethical compensation in the second column, and the log of the desired change in compensation in the third column. Panels (a) and (b) show coefficients related to individual and country-level regressors, respectively. Finally, panel (c) shows estimates of the random effects of the model (i.e. estimates of the standard deviations of the two components of the error term).

\section{Table 2}

As to the perception of the actual level of executive compensation, the first column of table 2 shows that, in general, almost all regressors at the individual-level have the expected sign and turn out to have a statistically significant effect on each of the four different dependent variables. For example, individuals who perceive a high spread in occupational wages in general also tend to perceive a high compensation for a chairman (the estimated elasticity of actual executive compensation with respect to overall perceived inequality perception is about 0.5 , as shown in the second row in column 1). More interestingly, the table also shows that individuals' perceptions about the determinants of pay are also relevant predictors of the perceived level of executive compensation. The actual level of executive pay is higher (lower) for those people who believe that ascribed (acquired) virtues are important for determining one's pay.

The most interesting estimates, however, are those that relate to the country-level regressors, which are shown in panel (c). We see that both of the objective, country-level inequality measures are significant predictors of the individual-level perception of executive pay. In fact,

\footnotetext{
${ }^{17}$ Obviously, it is not be possible to estimate the effects of any regressor at the country level if estimation is done by fixed effects estimation. However, I find that the estimated coefficients on the individual-level regressors from a fixed-effects model are very similar to the estimates from the random-effects models shown in table 2 below. This leads me to believe that country fixed-effects are probably not that important in the present analysis and that unobserved country differences are reasonably well captured by including the country-level regressors. The corresponding estimates from fixed-effects models are shown in appendix table B.2.
} 
the estimated elasticity of actual compensation with respect to the Gini (before taxes and transfers) is about 2.5. Furthermore, the difference in the Gini coefficient is also statistically significantly related to actual executive pay: average perception is lower in those countries where the difference between the two Gini coefficients is larger. Finally, the perceived level of executive pay is also higher in richer countries, everything else constant.

Column 2 shows corresponding estimates for the ethical compensation of top executives. Again, most individual-level regressors are statistically different from zero and have the expected sign. As for actual compensation, ethical executive compensation is higher for richer individuals and for those who are generally more tolerant towards pay differentials. Beliefs about which factors should be important in determining one's pay turn also out to be relevant predictors of the ethical level of executive pay. Specifically, individuals who believe that needs (effort) should be important in the determination of compensation tend to have a lower (higher) level of ethical executive compensation. With regard to the country-level regressors, we can see that ethical compensation is higher in more unequal countries (the elasticity of ethical pay with respect to the Gini before taxes and transfers is 1.5); the same is true for richer countries. Moreover, countries where the difference between the two Gini coefficients is larger tend to have lower estimates for ethical executive pay.

Finally, the dependent variable in the third column measures the discrepancy between a chairman's actual and ethical compensation. First, individuals' general perceptions and valuations of occupational wage differentials are important predictors of the desired change in executive pay. Desired changes in a worker's and coworker's wages turn also out to be significantly associated with the dependent variable. But, as above, the most interesting estimates are again those related to country-level regressors shown in panel (b). Individuals in countries with a less equal distribution of income (before taxes and transfers) or from richer countries tend to desire a larger reduction in executive pay. On the other hand, desired changes in executive pay tend to be smaller in countries with a high level of redistribution (as measured by the difference in the Gini coefficient).

\subsection{Subjective Estimates of Executive Pay and Political Preferences}

The next logical step is to study the relation between individuals' perceptions and normative valuations of executive pay and their political preferences with respect to state intervention and 
progressive taxation. Table 3 shows the link between individuals' subjective perceptions and valuations of executive compensation and their political preferences. Specifically, I estimate the strength of the association between individuals' estimates of executive pay and whether they agree with redistribution by the state or with progressive taxation. ${ }^{18}$

As above, I run random-effects regression models, this time including individuals' actual and ethical estimates of executive compensation as key explanatory variables: ${ }^{19}$

$$
p_{i j}=\left(\beta_{0}+z_{j} \gamma+\zeta_{j}\right)+x_{i j} \beta+\ln \left(y_{i j}\right) \delta+\epsilon_{i j},
$$

with $p_{i j}$ denoting some measure of political preferences of individual $i$ in country $j$. The control variables are the same as above, except that subjective estimates of executive pay are also included on the right-hand side of the regression equation and are denoted by $\ln \left(y_{i j}\right)$, and so the parameters of key interest are now given by $\delta$.

Table 3

The first two columns of table 3 show results for individuals' support for redistribution by the state. The parameter estimates associated with the perception and the normative valuation of executive compensation are shown in panel (a). These two estimates turn out to be highly significant in both statistical and substantial terms. The semi-elasticity of the support of redistribution by the state with respect to the actual level of executive pay is estimated to be 0.046 to 0.057 , and about -0.069 to -0.094 with respect to the ethical level of executive pay. ${ }^{20}$ Both estimates of executive pay are therefore important predictors of individuals' support for redistribution by the state.

Qualitatively similar results are found for individuals' support for progressive taxation of those individuals with higher incomes, as shown in columns 3 and 4 . The semi-elasticity of the

\footnotetext{
${ }^{18}$ Regarding state intervention, individuals were asked the following question in the survey: "How much do you agree or disagree: It is the responsibility of the government to reduce the differences in income between people with high incomes and those with low incomes." With respect to taxation, individuals were asked: "Do you think that people with higher incomes should pay a larger share of their income in taxes than those with low incomes, the same share, or a smaller share?" In both cases, I map individuals' ordinal degree of (dis)agreement with the statement on a simple binary indicator (i.e. a binary variable taking on the value 1 if an individual agrees or strongly agrees with the statement).

${ }^{19}$ One could also model individuals' estimates of executive pay as a function of their more general political preferences. In any event, I do not claim to estimate any causal effect within the present analysis.

${ }^{20}$ Thus the elasticity of support for redistribution by the state with respect to the estimate of actual executive pay is about 0.075 to 0.204 (evaluated at the corresponding mean of the dependent variable), while the elasticity with respect to ethical executive pay is about -0.247 to about -0.152 .
} 
support for progressive taxation with respect to the actual level of executive pay is 0.059 to 0.060 , and about -0.06 to -0.079 with respect to the ethical level of executive compensation. ${ }^{21}$ Again, there is a substantial and statistically significant association between the two estimates of executive pay and individuals' support for progressive taxation.

Overall, the results from table 3 show that there is a strong association between individuals' perceptions of actual and normative beliefs about ethical executive pay on the one hand and their more general political preferences on the other hand. On a more general level, the evidence presented in this paper is clearly also consistent with the view that individuals' preferences over redistribution (individuals' normative valuations of executive compensation can clearly be viewed as part of their more general attitudes towards redistribution) and the effective level of redistribution are linked through individuals' voting behavior (e.g. Borck, 2007).

\section{Conclusions}

This paper uses internationally comparable survey data to analyze individuals' subjective estimates of a chairman's compensation. Not surprisingly, an overwhelming majority of individuals believes that top executives earn more than they deserve from respondents' point of view. However, the analysis also shows that there is huge variation in the perception and in the normative valuation of executive compensation across both individuals and countries.

The econometric analysis shows that substantial differences in subjective perceptions of and beliefs about executive pay remain, even after accounting for various individual-level determinants, and that some of these remaining differences are associated with differences in the effective level of inequality and amount of redistribution. Specifically, the desired decrease in executive compensation is higher in those countries where the difference between inequality before and after taxes and transfer payments is large (i.e. where there is a lot of actual redistribution). I also find that there is a strong empirical association between individuals' subjective estimates of executive compensation and more general political preferences. Individuals who believe that top executives earn more than they deserve tend to be in favor of redistribution by the state and progressive taxation. It thus seems likely that people's perceptions and norma-

\footnotetext{
${ }^{21}$ The elasticity of the support for progressive taxation with respect to actual and ethical executive pay therefore ranges from 0.283 to 0.078 and from -0.329 to -0.080 , respectively, if evaluated at the sample mean of the dependent variable.
} 
tive evaluations of executive compensation feed back into the political process through their voting behavior, for example.

On a more general level, I think that the results presented in this study are also well in line with the idea that individuals' attitudes towards inequality and redistribution on the one hand and countries' redistributive policies on the other hand are likely to be determined simultaneously, as Alesina and Angeletos (2005) and Bénabou and Tirole (2006) argue, among others. Alternatively, it is conceivable that countries differ with respect to underlying social norms that affect the effective level of executive pay as well as compensation at the top end of the distribution more generally (Atkinson, 2003; Levy and Temin, 2007; Piketty and Saez, 2003), and that country differences in the ethical level of executive compensation at least in part reflect differences in more general norms across countries. 


\section{References}

Abowd, J. and Kaplan, D. (1999). Executive compensation: six questions that need answering. Journal of Economic Perspectives, 13(4), 145-168.

Alesina, A. and Angeletos, G.-M. (2005). Fairness and Redistribution. American Economic Review, 95(4), 960-980.

Atkinson, A. (2003). The changing distribution of income: evidence and explanations. German Economic Review, 1(1), 3-18.

Bebchuk, L. and Fried, J. (2003). Executive compensation as an agency problem. Journal of Economic Perspectives, 17(3), 71-92.

Bebchuk, L. and Grinstein, Y. (2005). The growth of executive pay. Oxford Review of Economic Policy, 21(2), 283-303.

Bénabou, R. and Tirole, J. (2006). Belief in a Just World and Redistributive Politics. Quarterly Journal of Economics, 121(2), 699-746.

Bertrand, M. and Mullainathan, S. (2001). Are CEOS Rewarded for Luck? The Ones without Principals Are. Quarterly Journal of Economics, 116(3), 901-932.

Borck, R. (2007). Voting, Inequality and Redistribution. Journal of Economic Surveys, 21(1), $90-109$.

Charness, G. and Levine, D. (2000). When are layoffs acceptable? Evidence from a quasiexperiment. Industrial and Labor Relations Review, 53(3), 381-400.

Clementi, G. and Cooley, T. (2009). Executive Compensation: Facts. NBER Working Paper No. 15426.

Conyon, M. and Murphy, K. (2000). The prince and the pauper? CEO pay in the United States and United Kingdom. Economic Journal, 110(467), 640-671.

Conyon, M., Gregg, P., and Machin, S. (1995). Taking care of business: Executive compensation in the United Kingdom. Economic Journal, 105(430), 704-714.

Cornelissen, T., Himmler, O., and Koenig, T. (2010). Perceived unfairness in CEO compensation and work morale. Economics Letters, forthcoming.

Frank, R., Gilovich, T., and Regan, D. (1993). Does studying economics inhibit cooperation? The Journal of Economic Perspectives, 7(2), 159-171.

Frydman, C. and Saks, R. (2010). Executive compensation: A new view from a long-term perspective, 1936-2005. Review of Financial Studies, 23(5), 2099-2138.

Gabaix, X. and Landier, A. (2008). Why Has CEO Pay Increased So Much? Quarterly Journal of Economics, 123(1), 49-100.

Gelman, A. and Hill, J. (2007). Data analysis using regression and multilevel/hierarchical models. Cambridge University Press New York.

Jasso, G. and Meyersson Milgrom, E. M. (2008). Distributive justice and CEO compensation. Acta Sociologica, 51(2), 123-143. 
Jensen, M. and Murphy, K. (1990). Performance pay and top-management incentives. Journal of Political Economy, 98(2), 225.

Kaplan, S. and Rauh, J. (2010). Wall Street and Main Street: What Contributes to the Rise in the Highest Incomes? Review of Financial Studies, 23(3), 1004-1050.

Levy, F. and Temin, P. (2007). Inequality and Institutions in 20th Century America. NBER Working Paper No. 13106.

Moulton, B. (1986). Random group effects and the precision of regression estimates. Journal of Econometrics, 32(3), 385-397.

Murphy, K. J. (1999). Executive compensation. In O. Ashenfelter and D. Card, editors, Handbook of Labor Economics, volume 3B, pages 2485-2563. Elsevier Science.

OECD (2008). Growing Unequal? Income Distribution and Poverty in OECD Countries. Technical report, Organization for Economic Co-operation and Development.

Osberg, L. and Smeeding, T. (2006). "Fair" Inequality? Attitudes toward Pay Differentials: The United States in Comparative Perspective. American Sociological Review, 71(3), 450473.

Piketty, T. and Saez, E. (2003). Income Inequality in The United States, 1913-1998. Quarterly Journal of Economics, 118(1), 1-39.

Rabe-Hesketh, S. and Skrondal, A. (2008). Multilevel and longitudinal modeling using Stata. Stata Press.

Whaples, R. (1995). Changes in attitudes among college economics students about the fairness of the market. Journal of Economic Education, 26(4), 308-313.

Zhou, X. (2000). CEO pay, firm size, and corporate performance: evidence from Canada. Canadian Journal of Economics, 33(1), 213-251. 
Table 1: Summary statistics

\begin{tabular}{|c|c|c|c|}
\hline & Mean & $\begin{array}{l}\text { Standard } \\
\text { deviation }\end{array}$ & $\begin{array}{c}\text { Intraclass } \\
\text { correlation }\end{array}$ \\
\hline \multicolumn{4}{|l|}{ (a) Estimates of chairman's compensation } \\
\hline Actual compensation & 9.060 & 9.374 & 0.152 \\
\hline Actual compensation $<1$ & 0.000 & 0.000 & \\
\hline Actual compensation $=1$ & 0.002 & 0.044 & \\
\hline Actual compensation $>1$ & 0.998 & 0.044 & \\
\hline Ethical compensation & 4.130 & 3.576 & 0.102 \\
\hline Ethical compensation $<1$ & 0.006 & 0.078 & \\
\hline Ethical compensation $=1$ & 0.019 & 0.135 & \\
\hline Ethical compensation $>1$ & 0.975 & 0.156 & \\
\hline Desired change in compensation & -0.425 & 0.532 & 0.063 \\
\hline Desired change $<0$ & 0.687 & 0.464 & \\
\hline Desired change $=0$ & 0.231 & 0.422 & \\
\hline Desired change $>0$ & 0.082 & 0.274 & \\
\hline Desired change (alternative measure) & -0.680 & 0.605 & 0.052 \\
\hline Desired change $<0$ & 0.876 & 0.329 & \\
\hline Desired change $=0$ & 0.074 & 0.261 & \\
\hline Desired change $>0$ & 0.050 & 0.218 & \\
\hline \multicolumn{4}{|l|}{ (b) Other subjective wage estimates } \\
\hline Actual wage spread & 17.952 & 23.371 & 0.176 \\
\hline Ethical wage spread & 8.184 & 8.604 & 0.112 \\
\hline Fairness evaluation (skilled worker) & 1.356 & 0.551 & 0.144 \\
\hline Fairness evaluation (own occupation) & 1.474 & 1.816 & 0.028 \\
\hline Actual wage (own occupation) & 1.435 & 14.127 & 0.001 \\
\hline \multicolumn{4}{|l|}{ (c) Other individual-level variables } \\
\hline Age (years) & 45.054 & 16.058 & 0.027 \\
\hline Education (years) & 12.742 & 4.540 & 0.399 \\
\hline Female $($ yes $=1)$ & 0.508 & 0.500 & 0.009 \\
\hline Perception: ascribed virtues are important & 3.181 & 0.886 & 0.108 \\
\hline Perception: acquired skills are important & 2.972 & 0.986 & 0.202 \\
\hline Belief: needs should be important & 3.234 & 1.056 & 0.050 \\
\hline Belief: effort should be important & 3.863 & 0.531 & 0.038 \\
\hline Perception of conflicts & 2.359 & 0.587 & 0.125 \\
\hline Social mobility & 0.024 & 1.828 & 0.070 \\
\hline \multicolumn{4}{|l|}{ (d) Country-level variabels } \\
\hline Gini, before taxes and transfers & 0.469 & 0.038 & \\
\hline$\Delta$ Gini (= Gini before - Gini after) & 0.171 & 0.048 & \\
\hline Real gross domestic product, per capita & $22,134.189$ & $7,343.204$ & \\
\hline Maximum number of individuals & & 15,377 & \\
\hline Maximum number of countries & & 15 & \\
\hline
\end{tabular}

Notes: The intraclass correlation is defined as the ratio of the variance of country means to the overall variance of a variable. Variable definitions are given in the main text and in appendix A. Data sources of aggregate-level variables are listed in footnote 15. 


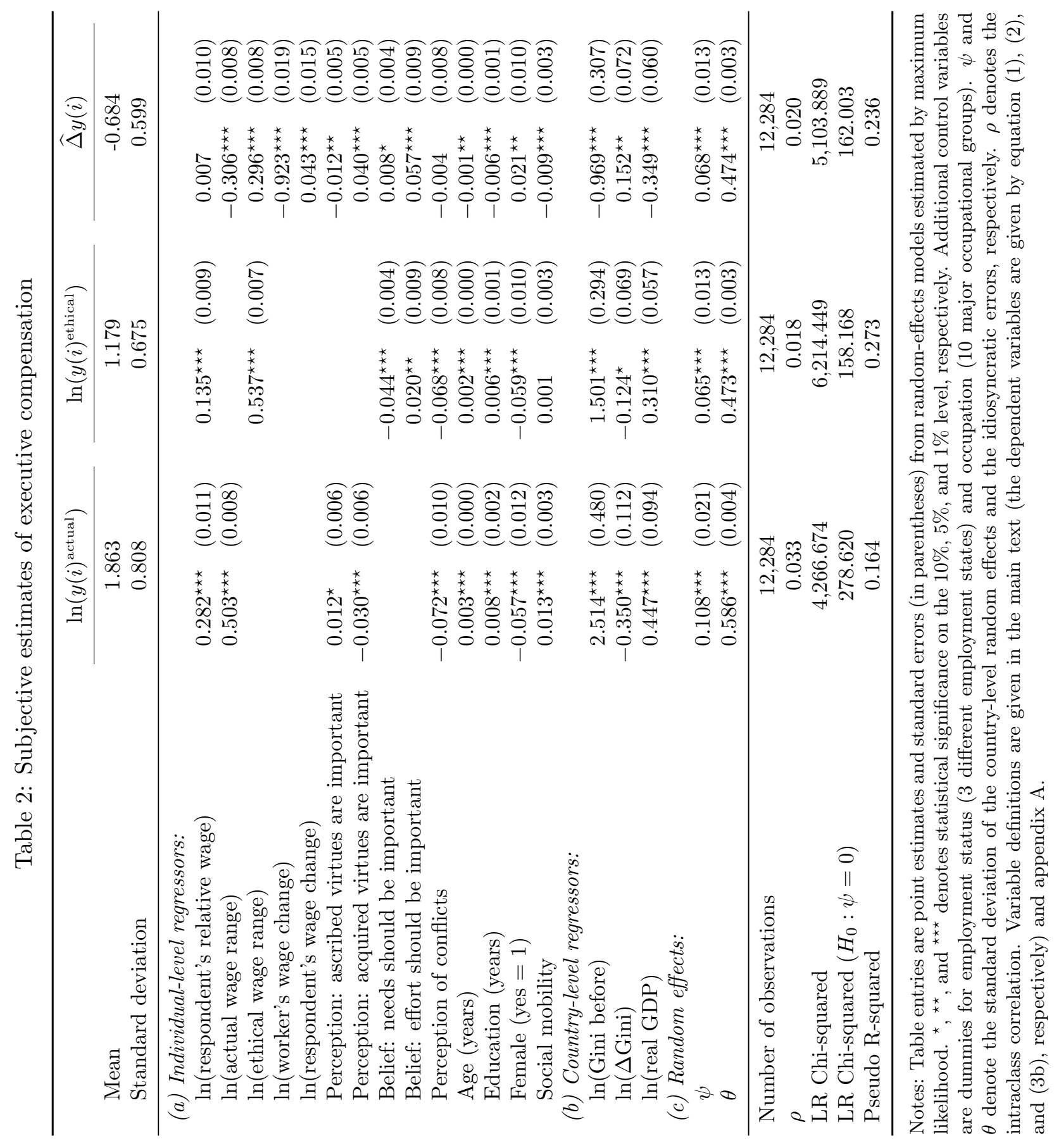




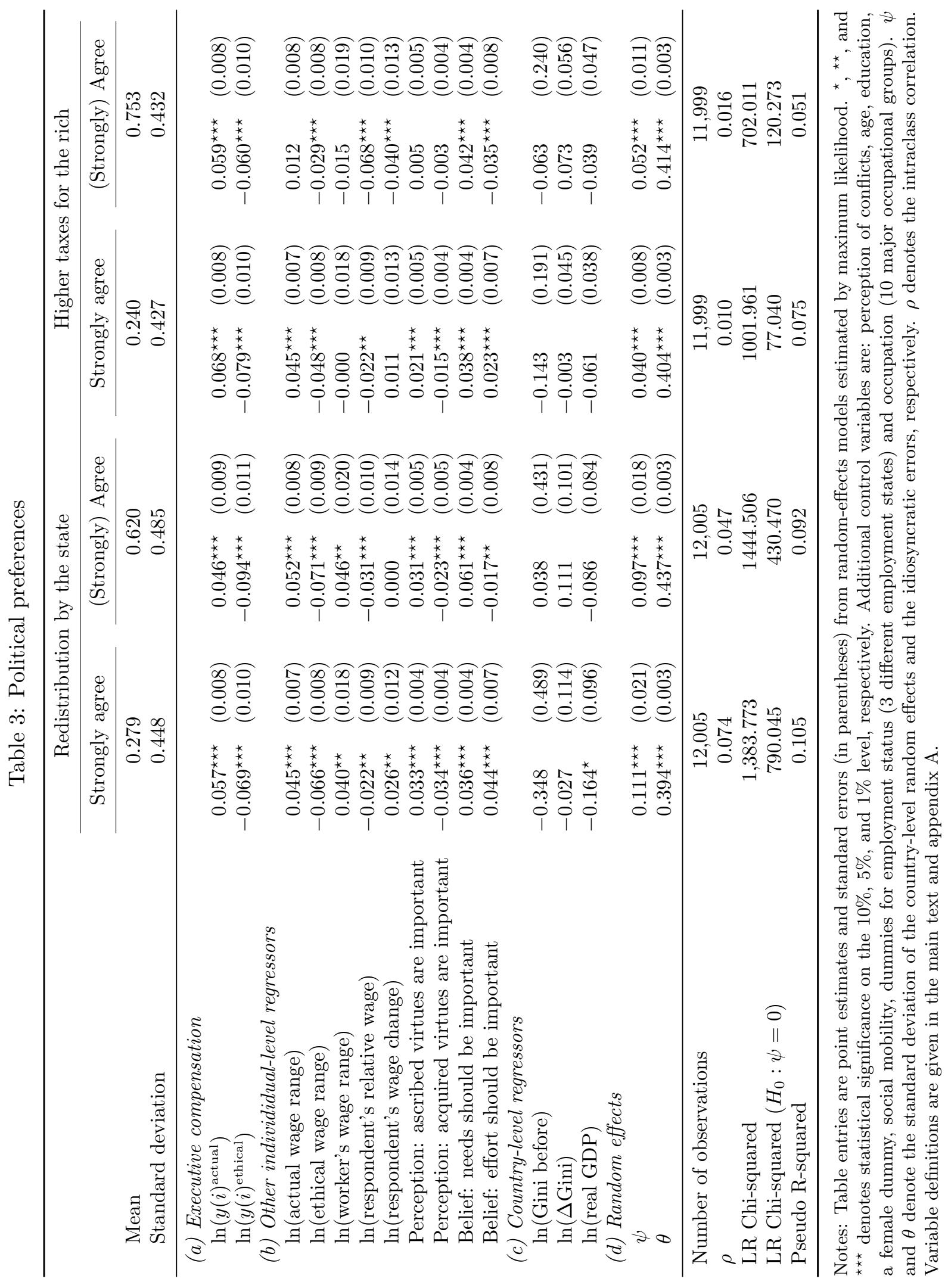




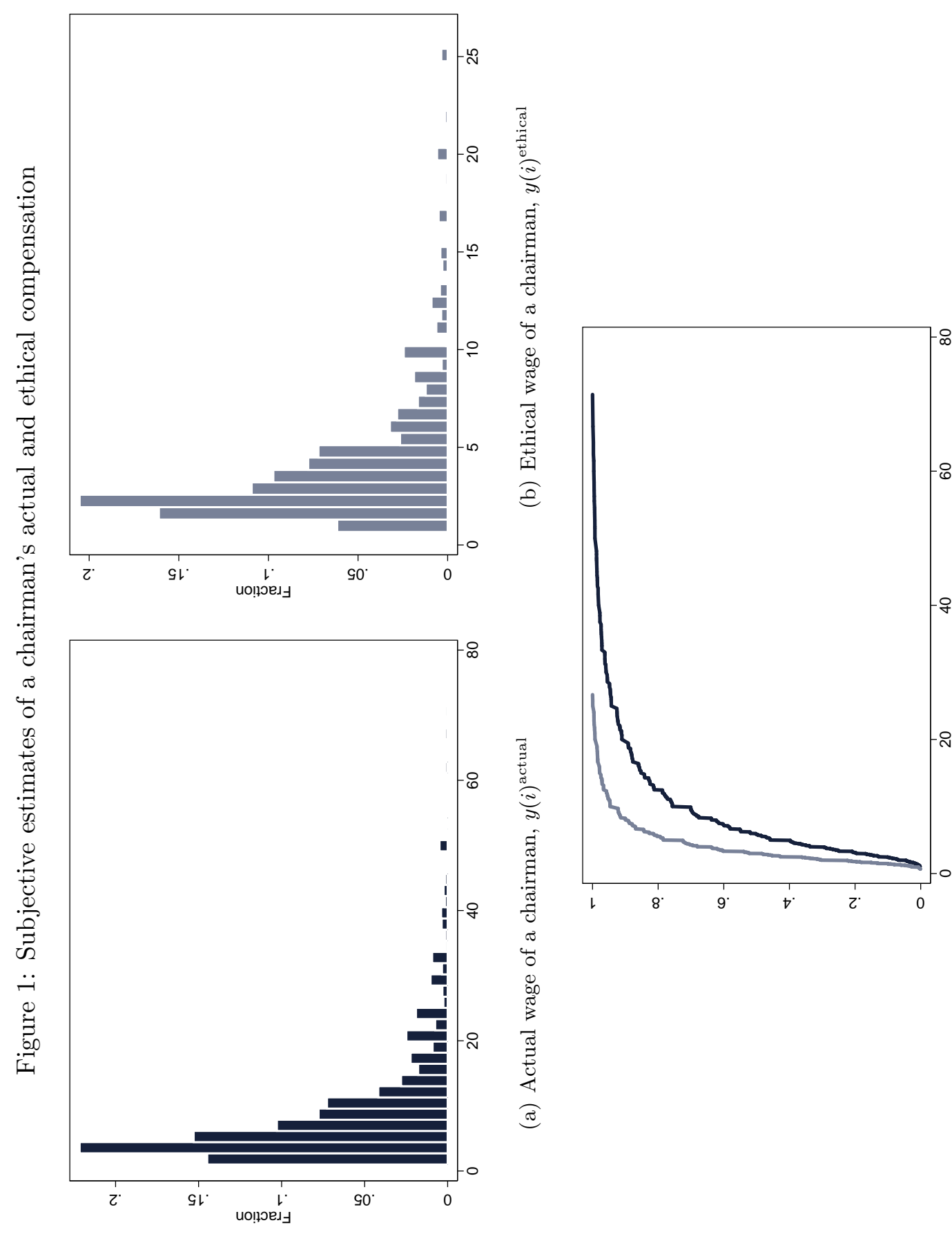




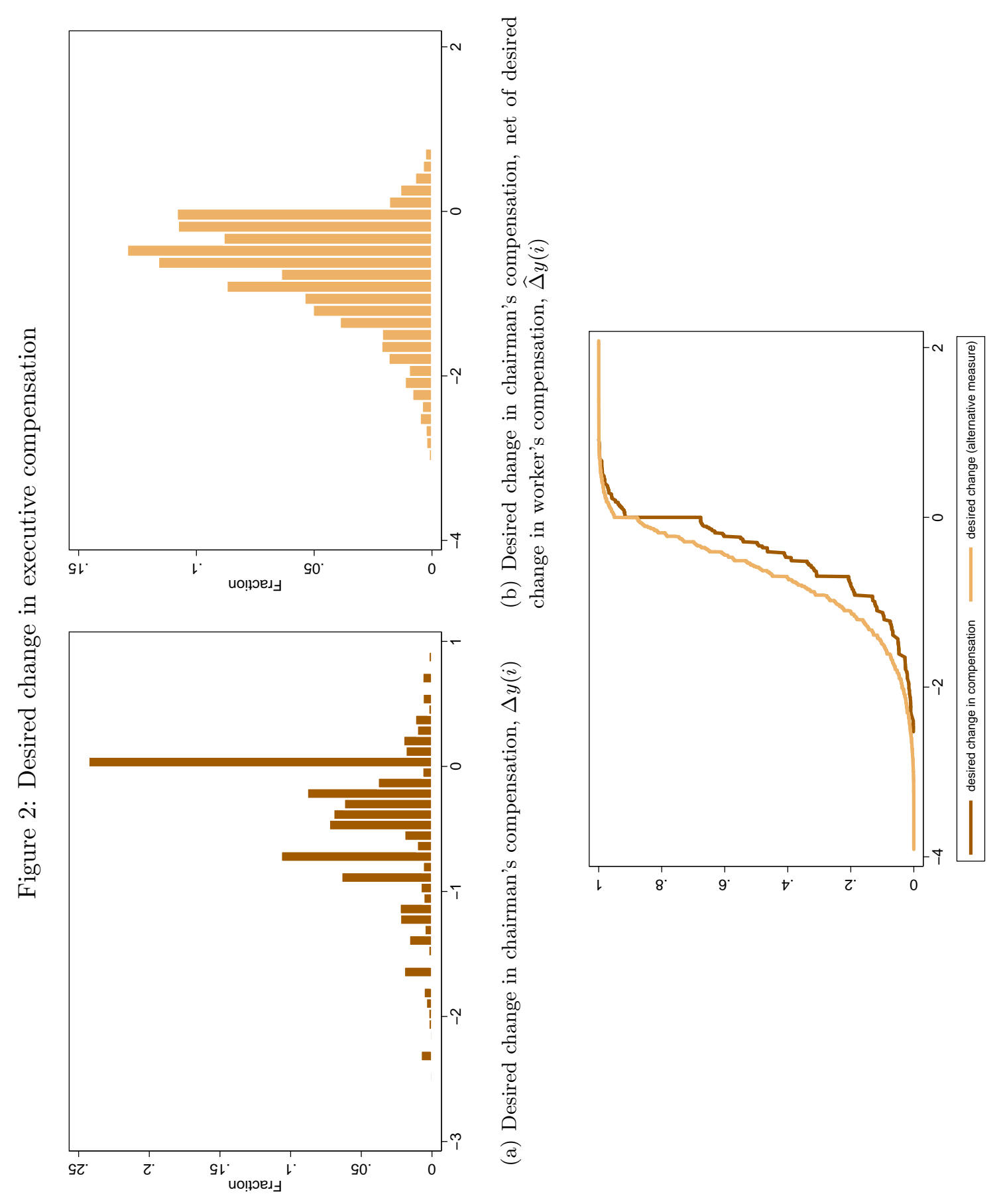




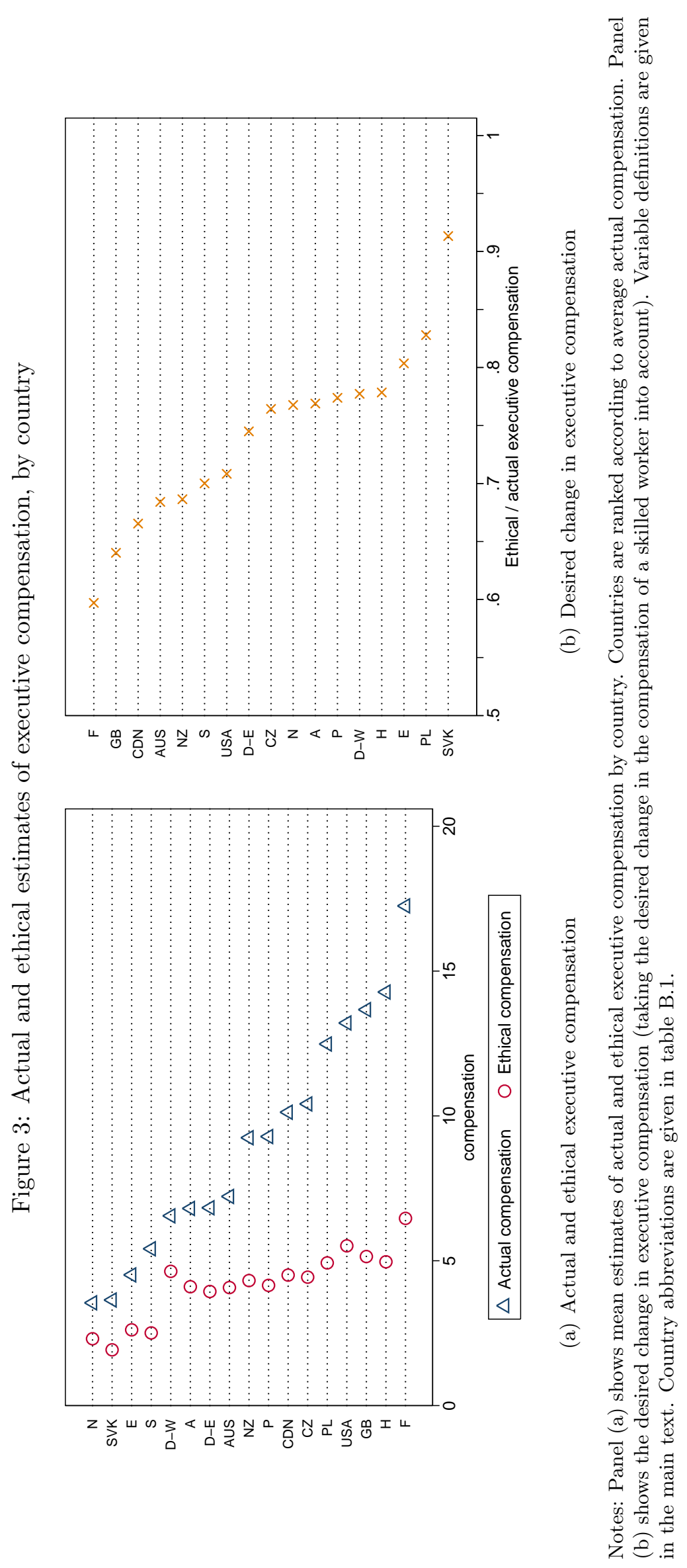




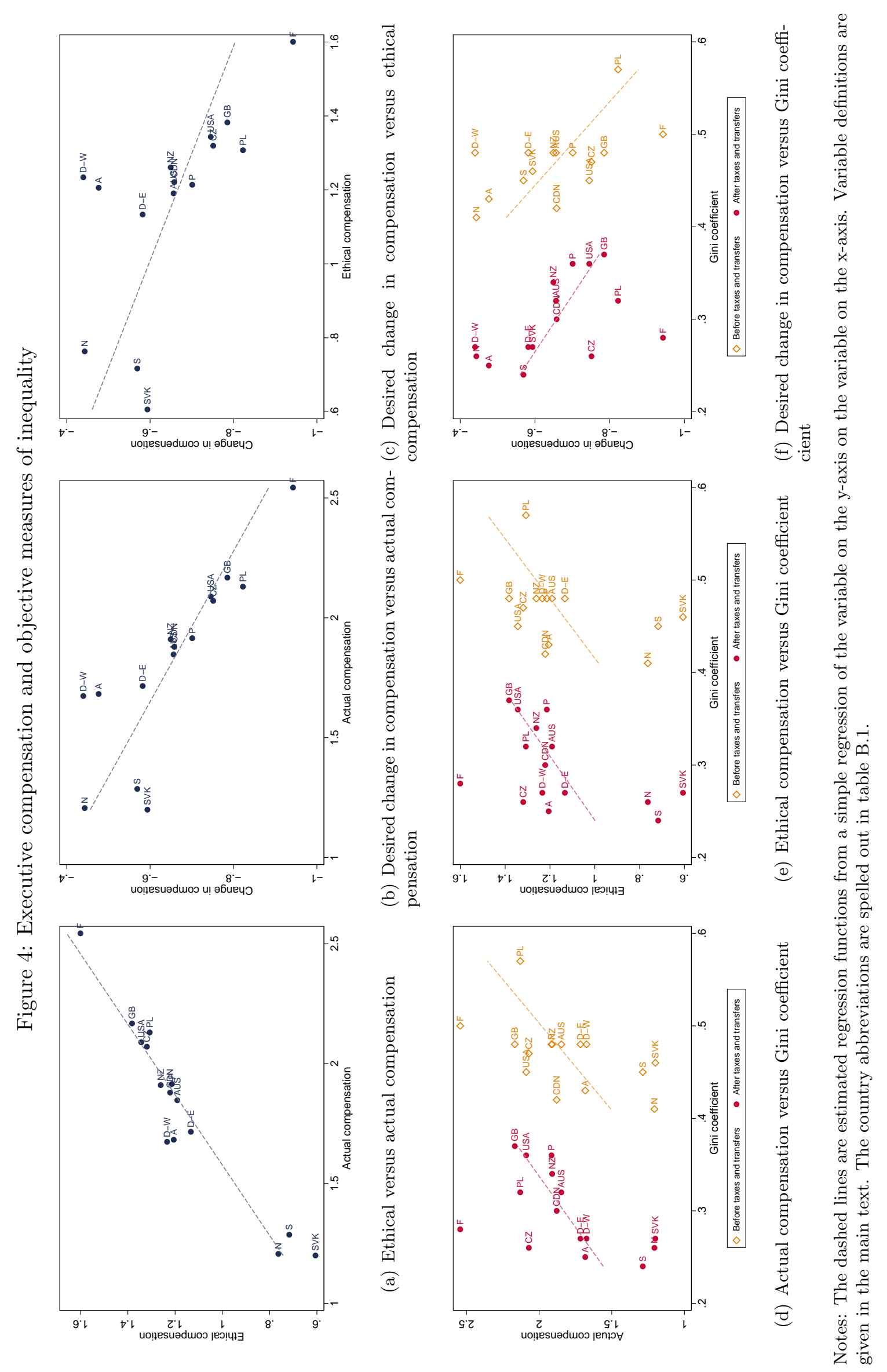




\section{A Variable Definitions}

\section{A.1 Variables Constructed From Individuals' Wage Estimates}

I use some additional measures involving individuals' subjective wage estimates in the empirical analysis. The first variable ("respondent's relative wage") simply measures respondents' actual compensation relative to the wage of a skilled worker.:

$$
y(i)=y(i)_{\text {respondent }}^{\text {actual }} / y(i)_{\text {worker }}^{\text {actual }}
$$

The second measure ("respondent's wage change") describes an individual's satisfaction with his or her own pay by comparing actual and ethical wage estimate for one's coworkers:

$$
\Delta y(i)_{\text {respondent }}=y(i)_{\text {respondent }}^{\text {ethical }} / y(i)_{\text {respondent }}^{\text {actual }}
$$

Similarly, I measure an individual's desired change in the compensation of a skilled worker ("worker's wage change"):

$$
\Delta y(i)_{\text {worker }}=y(i)_{\mathrm{worker}}^{\mathrm{ethical}} / y(i)_{\mathrm{worker}}^{\mathrm{actual}}
$$

Finally, I use two additional measures that capture individuals' estimates of the overall wage spread with respect to both actual and ethical wages ("actual wage range" and "ethical wage range", respectively):

$$
\begin{aligned}
& r(i)^{a}=y(i)_{\max }^{\text {actual }} /\left(y(i)_{\min }^{\text {actual }}, \quad\right. \text { and } \\
& r(i)^{e}=y(i)_{\max }^{\text {ethical }} /\left(y(i)_{\min }^{\text {ethical }},\right.
\end{aligned}
$$

where $y(i)_{\max }^{w}$ and $y(i)_{\min }^{w}$ denotes an individual's highest and lowest wage estimate across the different occupations, respectively, excluding his or her estimates of executive compensation.

\section{A.2 Perceptions and Beliefs}

Needs: This variable captures the degree to which an individual thinks that one's needs should be important in determining their income (need principle). This variable is constructed from the following two survey questions about the factors that should be important in determining one's pay: "In deciding how much people ought to earn, how important should each of these things be, in your opinion? (i) What is needed to support your family. (ii) Whether the person has children to support." Possible numerical answers range from 1 ("strongly disagree") to 5 ( "strongly agree") for each survey item. The variable constructed from these items corresponds to the simple average across items.

Effort: This variable is meant to capture the equity principle and is constructed from five survey questions on factors that should be important in determining pay: "In deciding how much people ought to earn, how important should each of these things be, in your opinion? (i) How much responsibility goes with the job. (ii) The number of years spent in education and training. (iii) Whether the job requires supervising others. (iv) How well he or she does the job. (v) How hard he or she works at the job." Possible numerical answers range from 1 ( "strongly disagree") to 5 ("strongly agree") for each survey item. The variable constructed from these items corresponds to the simple average across items.

Ascribed skills: This variable measures the extent to which a person beliefs in ascribed factors as being important in determining the amount of compensation. This question relates 
to the perception of individuals of which factors actually are important for getting ahead. "We have some questions about opportunities for getting ahead: (i) How important is coming from a wealthy family? (ii) Knowing the right people?" Possible answer categories range from 1 ( "strongly disagree") to 5 ("strongly agree") for each survey item. The variable constructed from these items corresponds to the simple average across items.

Acquired skills: This variable measures if an individual thinks that acquired skills are actually important in determining one's pay. The variable is constructed from two different questions: "We have some questions about opportunities for getting ahead: (i) Do you agree or disagree? In Switzerland, people get rewarded for their effort. (ii) In Switzerland, people get rewarded for their intelligence and skills." Possible answer categories range from 1 ("strongly disagree") to 5 ("strongly agree") for each survey item. The variable constructed from these items corresponds to the simple average across items.

\section{A.3 Additional Control Variables}

Mobility: The only information about individuals' mobility available in the survey are two questions about their self-perception of their social position today and their position ten years ago: "(i) In our society, there are groups which tend to be towards the top and groups which tend to be toward the bottom. Below is a scale that runs from top to bottom. Where would you put yourself on this scale? (ii) And ten years ago, where did you fit then?" Both are measured on a scale ranging from 1 (bottom) to 10 (top). The mobility scale used simply is defined as the difference between the two scores (i.e. position today minus position ten years ago).

Conflict: This variable measures individuals' perceptions of conflicts within society. Included items are questions about the existence of conflicts between: "In all countries, there are differences or even conflicts between different social groups. In your opinion, in (respondent's country) how much conflict is there between...: (i) Poor people and rich people? (ii) The working class and the middle class? (iii) Management and workers? (iv) People at the top of society and people at the bottom? (v) Young people and older people?" Possible answer categories range from 1 ("strongly disagree") to 5 ("strongly agree") for each survey item. The variable constructed from these items corresponds to the simple average across items.

Employment status: Employment status is represented by three dummy variables indicating either (i) employment, (ii) unemployment, or (iii) not in the labor force.

Occupation: Ten dummy variables indicating occupation according to the International Standard Classification of Occupations (ISCO). For example, the first major group in the classification comprises "legislators, senior officials and managers". 


\section{B Additional Tables}

Table B.1: Effective sample size, by country/region

\begin{tabular}{llr}
\hline Country/region & Abbreviation & Valid observations \\
\hline Australia & AUS & 1,265 \\
Austria & A & 408 \\
Canada & CND & 748 \\
Czech Republic & CZ & 1,524 \\
France & F & 1,491 \\
East Germany & D-E & 200 \\
West Germany & D-W & 325 \\
Great Britain & GB & 573 \\
New Zealand & NZ & 920 \\
Norway & N & 1,006 \\
Poland & PL & 400 \\
Portugal & P & 752 \\
Slovakia & SVK & 920 \\
Sweden & S & 914 \\
United States & USA & 838 \\
\hline Total & & 12,284 \\
\hline
\end{tabular}

Notes: The number of valid observations refers the number of observations that are actually used in the main empirical analysis. 


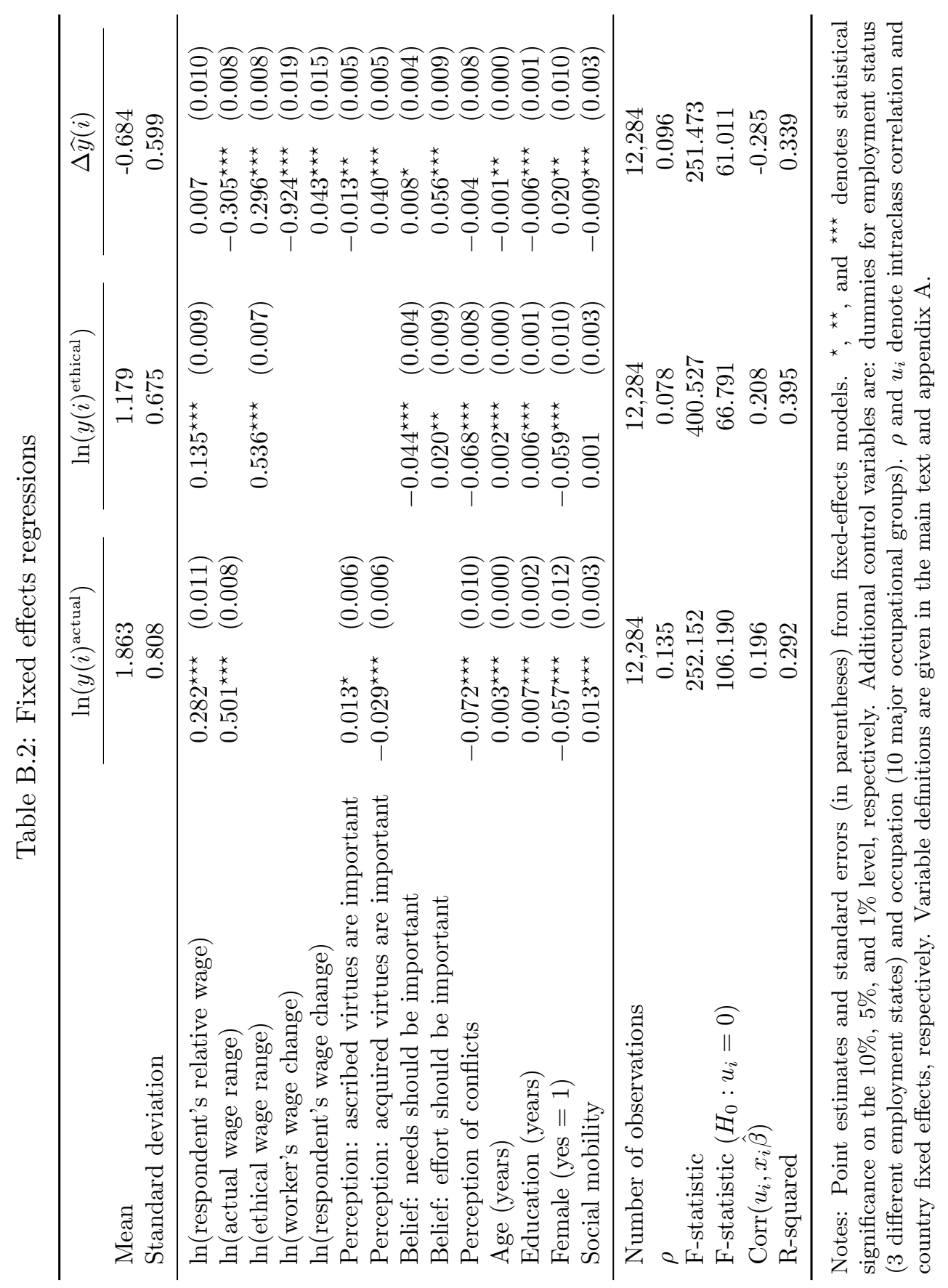

